\title{
La Traducción De La Argumentación En EI Texto Periodístico Español/Árabe Y La Aplicación De Las Técnicas Específicas De Traducción
}

\author{
Dr. Moulay-Lahssan Baya E. PhD \\ Universidad de Granada, Spain
}

doi: 10.19044/esj.2016.v12n26p73 URL:http://dx.doi.org/10.19044/esj.2016.v12n26p73

\begin{abstract}
This research aims at presenting the importance of the journalistic translation from Spanish into Arabic. It pretends to present this topic through two main axes. The first axe presents a contextualization of journalistic genre in a very particular way; the argumentative genre as the main axe of our research. The second axe of this work, which has been very practical, after defining and exposing the characteristics of argumentative text, focuses on the application of specific techniques of journalistic translation, which are basically, amplification, compression and omission. Therefore, we have chosen a mass media of great international projection: Project Syndicate; an international organization that has the largest source of world opinion articles in different languages, signed by eminent intellectuals and specialists in different fields of knowledge. Subsequently, we proceeded to the selection of news argumentative and we have analyzed the translation technique used in each case, with its pertinent comments as final results of the study.
\end{abstract}

Keywords: Journalistic Translation, Spanish/Arabic, argumentative text, translation techniques, Project Syndicate

\section{Resumen}

En esta investigación, que gira en torno a la traducción periodística en el binomio español-árabe, hemos intentado abordar este asunto centrándonos en dos cuestiones específicas. Por un lado, hemos llevado a cabo una contextualización del género literario periodístico, y hemos dirigido nuestro interés, de manera muy particular, hacia el género argumentativo como tema principal de nuestro trabajo de campo. Por otro lado, es decir, en la segunda parte de este trabajo, que ha tenido un carácter eminentemente práctico, tras definir y exponer las características del texto argumentativo, nos hemos centrado en la aplicación de las técnicas específicas de la traducción periodística, que son, básicamente, la amplificación, la compresión y la 
elisión. Para ello, hemos escogido un medio de comunicación de gran proyección internacional: Project Syndicate, una organización internacional que posee la mayor fuente de artículos de opinión del mundo, en distintos idiomas, firmados por ilustres intelectuales y especialistas en distintos campos del saber. Posteriormente, hemos procedido a la selección de las noticias de carácter argumentativo y hemos analizado la técnica de traducción utilizada en cada caso, con el correspondiente comentario.

Palabras clave: Traducción periodística, español/árabe, texto argumentativo, técnicas de traducción, Project Syndicate

\section{Introducción}

En las dos últimas décadas, hemos sido testigos de la aparición de numerosos trabajos de investigación, en su mayoría académicos, en el campo de la traducción periodística, en concreto, en la combinación español-árabeespañol. Se ha tratado, básicamente, de tesis doctorales, trabajos fin de máster y trabajos fin de grado, y se han abordado temáticas muy variadas y de suma importancia. No obstante, estos trabajos no han sido ampliamente difundidos, y se han mantenido "ocultos" en las estanterías de las bibliotecas de los centros universitarios donde han sido defendidos, con posibilidades remotas de ser publicados. La temática abordada, por citar alguna a modo de ejemplo, varía desde la traducción de la exposición y la argumentación en la prensa árabe (Mezel, 2012) hasta la traducción de los elementos culturales árabes en el texto periodístico español (Cheikhna Baba, 2011), pasando por trabajos como el proceso de producción y traducción de la información en la Agencia Marroquí de Noticias (Safaa El Khaoua y Asmae Lahmidi, 2014).

Desde el punto de vista de la investigación en este campo, cabe destacar que la evolución también ha sido muy positiva, aunque los investigadores con más constancia y prolijidad en la temática objeto de estudio no han sido abundantes, salvo en casos muy contados (Derwish, 2004, 2005; Hernández Guerrero 2008, 2005, 2006; Baya 2007, 2015).

En el presente artículo, que gira alrededor de la traducción periodística en la combinación español-árabe, abordaremos dos cuestiones específicas: en una primera parte, efectuaremos una contextualización del género literario periodístico, y nos centraremos, de manera muy particular, en el género argumentativo como tema capital de nuestro trabajo de campo; y en la segunda parte, que tendrá un carácter fundamentalmente práctico, profundizaremos, tras determinar y presentar las características del texto argumentativo, en la aplicación de las técnicas específicas de traducción periodística (la amplificación, la compresión y la elisión). El medio de comunicación escogido, en este caso, es la organización internacional Project Syndicate, que cuenta con la mayor fuente de artículos de opinión del mundo. Posteriormente, 
hemos procedido a la selección de las noticias de carácter argumentativo y hemos analizado la técnica de traducción utilizada en cada caso, con el correspondiente comentario.

Los artículos seleccionados se regirán por unos parámetros de búsqueda previamente establecidos y se extraerán de las secciones de Estrategias Globales y/o Economía Internacional, al ser estas las más leídas y visitadas, a nuestro juicio, entre las informaciones de carácter argumentativo.

Cabe señalar que, en un principio, teníamos pensado centrar el trabajo en una o dos agencias internacionales de noticias, pero, desafortunadamente, tras realizar una consulta exhaustiva en agencias como Reuters, AFP o la cadena Euronews, no pudimos encontrar artículos de opinión para su estudio y análisis; algo totalmente distinto de lo que ocurre con las noticias de carácter informativo o interpretativo, que sí aparecen en ambas lenguas (español/árabe).

Ante este contratiempo, decidimos explorar otra alternativa: buscar artículos de opinión en un periódico o en una cadena de televisión de alcance internacional y luego intentar localizar su versión traducida en otro medio también con idénticas características de garantía y fiabilidad. Tampoco dio su fruto. Finalmente, pudimos dar con el valioso material que atesora la organización Project Syndicate, en cuanto se refiere a artículos de opinión, comentarios y análisis, realizados por expertos, estadistas, economistas, etc., que abordan temas de máxima actualidad internacional.

\section{Objetivo y metodología}

Nuestra principal intención en este artículo es exponer, de forma muy breve, el estado de la cuestión de la traducción de textos periodísticos argumentativos en la combinación lingüística español-árabe, por un lado, y analizar las técnicas específicas de la traducción periodística y aplicarlas a un texto escrito, originalmente, en lengua española, y traducido posteriormente al árabe. Para ello, tendremos, grosso modo, en cuenta los siguientes aspectos: rasgos distintivos de la traducción periodística; características y análisis del texto argumentativo/valorativo; exposición y aplicación de las técnicas específicas de la traducción periodísticas a esta tipología textual.

En cuanto a la metodología adoptada para la selección y posterior análisis de los textos argumentativos estudiados, se han seguido, en líneas generales, los siguientes parámetros: consulta en la web de Project Syndicate noticias originales en árabe/español y su correspondiente traducción al español/árabe; elección solamente de noticias de carácter argumentativo; la búsqueda abarcará el período comprendido entre enero de 2014 y julio de 2016, es decir, dos años y medio exactamente; inclusión en cada noticia de los siguientes datos: título, autor, fecha de publicación y traducción (si consta); subrayado de la información que aparece en la noticia original y no recogida 
en la versión traducida; aplicación de las técnicas de traducción a todas las noticias seleccionadas; análisis y comentario de los resultados obtenidos.

\section{El texto argumentativo}

Los textos periodísticos se clasifican, generalmente, en textos de información y textos de opinión, aunque no existe plena unanimidad sobre esta división, y sobre qué variedad textual se englobaría en uno u otro grupo. Autores como Casasús y Núñez Ladevéze (1991:88) introducen tres categorías dentro del género periodístico (géneros informativos, géneros interpretativos y géneros argumentativos), y otros como (Hatim y Mason, 1995) destacan que la hibridación en la tipología textual es la regla y no la excepción, ya que, en muchos casos, las asimilaciones o fronteras entre un género y otro desaparecen y surgen tipos textuales a caballo entre dos textos (Guerrero, 2005: 89). En esta línea, cabe mencionar la clasificación aportada por Leñero y Marín (1986: 37, apud Ghignoli y Montabes, 2014: 390), que ofrecen una visión escueta de los géneros periodísticos, conformada a través de las aportaciones de otros estudiosos dando lugar a una mixtura (géneros informativos, géneros opinativos y géneros híbridos).

La argumentación, englobada dentro de los géneros argumentativos, ha sido estudiada y definida por varios autores (Toulmin, 1958; Beaugrande y Dressler, 1981; Biber, 1988; Hatim, 1997), etc., que coinciden, en líneas generales, en que esta deber ser concebida como una forma del discurso o, más bien, el uso del lenguaje para justificar o refutar un punto de vista político o ideológico, con el fin de alcanzar un consenso en los puntos de vista. La estructura del texto argumentativo o valorativo es más flexible, en comparación con el texto no valorativo o expositivo, ubicado dentro de los géneros informativos, tal y como afirma Hatim (1997: 103):

Text structure in this evaluative kind of context is bound to be more marked. The report could start off with the details and build up to reach some form of a summing - up which could easily have been an initial scene-setter. It could also employ structures borrowed from other text types such as counter-argumentation.

Cabe señalar que en la estructura del texto argumentativo la frase nominal determina también su textura dentro de los componentes de la argumentación que son: los elementos, las secuencias y los textos.

\section{Rasgos distintivos de la argumentación}

El género argumentativo u opinativo, según la clasificación propuesta por Peñaranda (2012), que fusiona las ideas de Torrico (1989) y Müler (1990), se utiliza para dar a conocer "ideas" y "opiniones" en contraposición con el reflejo de los hechos. Las opiniones pueden estar ancladas en los valores, ideas 
y sentimientos del autor de los textos, y no necesariamente en los hechos (apud Ghignoli y Montabes, 2014: 390).

Hatim (1997, 1989) distingue dos tipos de argumentación: la contraargumentación (al-ŷadal al-mu'ārị̣) y la argumentación a fondo (alýadal al-mubāšer). Es obvio que cada lengua posee unas convenciones retóricas exclusivas, ya que difieren en su orientación hacia el lector y en la manera en que las ideas se presentan y se organizan. En este sentido, Trotter (2000: 238) afirma que la lengua árabe difiere del español o el inglés en la redacción de los artículos de opinión, dado que en la lengua árabe prevalece el uso de los pronombres, la repetición léxica o las conjunciones aditivas, mientras que el español, al igual que el inglés, tiende a utilizar más las colocaciones léxicas. Por ello, la lengua árabe propende a expresar el formato de la argumentación a fondo más que el de la contraargumentación, que es típico, por ejemplo, en la prensa inglesa. La argumentación a fondo es el tipo de texto más característico de la lengua árabe, y su máxima representación la encontramos en los artículos de opinión. En el árabe estándar moderno queda claramente reflejada en el uso y en la función de los concesivos explícitos como aunque, a pesar de, mientras que, etc., sin embargo, no disponemos, hasta la fecha, de ninguna investigación empírica que se haya llevado a cabo para apoyar esta afirmación (Mezel, 2012).

En este trabajo, nos centraremos en el artículo de opinión, que se define, en líneas generales, como un artículo publicado por cualquier medio de comunicación y en distinto formato textual (en papel o soporte electrónico), que no necesariamente expresa la opinión del editor o el director del medio en cuestión, y que suele ir firmado por su autor. Engloba temas y contenidos muy variados (política, economía, sociedad, etc.) y su autor goza de un alto grado de libertad para expresar su opinión sobre un hecho ya sea de actualidad inmediata o no. En este sentido, Víctor Rodríguez propone la siguiente definición para el artículo: "Género periodístico que no tiene como fin principal informar al lector, sino formar su opinión sobre hechos importantes de actualidad" (1991:164, apud Ghignoli y Montabes, 2014: 393).

\section{Traducción de la argumentación}

La traducción periodística concebida como una actividad profesional que se remonta a tiempos muy lejanos y se ofrece en distintos contenidos y formas, sigue sin gozar del reconocimiento que se merece (Ghignoli y Montabes, 2014), y sin recibir, hasta la fecha, la atención necesaria por parte de los estudios traductológicos (Hernández, 2008). Sus particulares características, dependiendo de si estamos ante un texto de carácter informativo o valorativo, hacen que su traducción a otra lengua pueda variar sustancialmente. En esta dualidad y en lo que respecta a la tipología textual, el factor tiempo desempeña un rol también decisivo a la hora de la confección 
de la información. La dedicación no es la misma para un artículo de opinión que para una noticia de carácter meramente informativo. En el primer caso, donde se suele disponer de más tiempo para la elaboración del trabajo, se debe cuidar, en la medida de lo posible, las intenciones, el estilo propio de su autor, amén de otros aspectos, mientras que en el otro extremo, la presión de tiempo cobra suma importancia, debido a la creciente competencia con otros medios, generalmente agencias de noticias, por publicar cuanto antes la noticia en sus formatos textuales más urgentes -flash, boletín o, simplemente, los avances(Baya, 2005). A esto hay que añadir que los textos periodísticos que más se traducen son los que pertenecen al género argumentativo, tratándose principalmente de artículos de opinión, con un porcentaje que oscila entre el 70 y el $90 \%$ del total de las traducciones (Hernández, 2005: 93).

En el caso que nos ocupa, o sea, el proceso de traducción de la argumentación, Hatim (1997: 212) aborda, entre otras cuestiones, un problema que afecta, de forma particular, a la traducción al árabe, y confirma que dicha lengua tiende hacia la expresión explícita de las relaciones entre el discurso y los conectores discursivos. En muchos de los artículos de opinión consultados, se puede observar la existencia de partículas de justificación tal como destaca Hatim (ibid: 217), por ejemplo فإن exactos en inglés ni tampoco en español. Cuando se trata de la traducción de un artículo de opinión, escrito originalmente en lengua árabe, se recomienda al traductor de turno señalar la presencia de dichas partículas en el texto árabe y luego buscar la forma más óptima de reflejar su existencia en el texto traducido al español, a través, por ejemplo, del uso de caracteres en negrita o cursiva, etc. (Mezel, 2012).

Otro problema que suele surgir durante la traducción de esta variedad textual está relacionado con el factor espacio que se asigna al texto traducido. No obstante, con el uso cada vez más extendido de los formatos electrónicos, este impedimento empieza a cobrar menos relevancia. De todos modos, es recomendable en la traducción de los artículos de opinión, y en otras variedades textuales similares, sobre todo en el caso de las crónicas, que se respete el punto de vista vertido por el autor; y de ahí que la técnica más usada sea la traducción literal (Ghignoli y Montabes, 2014), con el fin de garantizar la máxima fidelidad al texto original.

\section{Técnicas específicas de traducción periodística}

En este apartado expondremos de forma muy breve, las técnicas de traducción periodísticas más comunes en el texto periodístico, por un lado, y trataremos de contextualizar su uso en un texto argumentativo/valorativo, por otro, con el fin de allanar el camino para su aplicación práctica a los artículos de opinión seleccionados para nuestro estudio y análisis. 


\section{Las técnicas de traducción y el texto argumentativo/valorativo}

La traducción periodística va muy ligada al género periodístico en cuestión, ya que no es lo mismo traducir un texto de carácter informativo no valorativo que otro de naturaleza argumentativa o valorativa. Por ello, es primordial adoptar, de partida, la técnica de traducción más adecuada para su aplicación en cada situación. En este caso, las técnicas específicas de traducción periodística que más se utilizan y sobre las que existe amplio consenso son las siguientes: amplificación, compresión y elisión (Hernández, 2006). Estas técnicas específicas se han definido, básicamente, como un "procedimiento, generalmente verbal, visible en el resultado de la traducción, que se utiliza para conseguir la equivalencia traductora" con unas características básicas (Hurtado Albir, 2001: 268). Cabe destacar que estas técnicas de traducción no cobran la misma importancia y tienen el mismo peso específico en el texto expositivo y argumentativo, ya que las modificaciones, en el caso del texto valorativo, son mínimas en cuanto a su traducción, y la tarea de traslación es muy elaborada, y donde el respeto al texto original llega a su máximo exponente (Hernández, 2006: 135).

La amplificación es una técnica abundantemente utilizada en la traducción de textos periodísticos y se basa, fundamentalmente, en la introducción de precisiones e información complementaria en el texto base (Hernández, 2006). En cambio, la compresión o reducción tiene lugar cuando el traductor se ve obligado, por necesidades relacionadas básicamente con el formato final del texto meta, a resumir o sintetizar parte del texto original. En cuanto a la técnica de la elisión, se relaciona más directamente con el espacio reservado al texto traducido, en comparación con el original, y ante esta situación, el traductor se ve obligado a prescindir de una parte importante del texto origen. Sin embargo, esta decisión afecta, de forma distinta, a cada género periodístico. Si en los textos de carácter expositivo a penas se percibe su aplicación, en el texto valorativo o argumentativo sí puede ser relevante, ya que afecta, sin lugar a dudas, al conjunto de la argumentación esgrimida y haría más difícil la compresión del texto final.

La parte práctica de este trabajo, que ya adelantamos, se va a centrar en exponer, por un lado, artículos de opinión traducidos del árabe al español o viceversa por un mismo medio de comunicación, y luego comprobar qué técnicas se han llevado a cabo durante el proceso de su producción en la lengua meta. Cabe señalar que, en líneas generales, los traductores, que se dedican a la traducción de esta variedad textual, optan por respetar el estilo del autor, al tratarse, como es sabido, de profesionales de mucho prestigio y con un recorrido amplio en su disciplina. No obstante, al igual que ocurre con otros géneros periodísticos, esta tipología textual puede, en algunos casos, sufrir "mutilaciones" tal y como afirma Hernández (2005: 132): 
Sin embargo, como el resto de los géneros periodísticos, no escapan a las transformaciones impuestas por el nuevo medio que las publica, aunque esos sí, en menor medida. [...] Es poco frecuente que estos textos sufran mutilaciones por motivos de espacio, pero sí pueden experimentar algunas adaptaciones debidas al nuevo receptor, a la nueva situación espacio-temporal y, por supuesto, a su nuevo canal.

\section{Aplicación de las técnicas a los textos seleccionados. Análisis de los resultados obtenidos}

En este apartado, procedemos a la aplicación de las técnicas y estrategias de traducción comentadas más arriba a los artículos de opinión extraídos del medio objeto de estudio.

En la búsqueda llevada a cabo para localizar artículos de opinión en la combinación lingüística español/árabe, traducidos a una de estas lenguas en la plataforma de Project Syndicate, en el período comprendido entre enero de 2014 y julio de 2016, hemos seleccionado textos que consideramos representativos para el estudio y análisis de la parte práctica. En total, hemos contabilizado alrededor de 45 artículos de opinión, extraídos básicamente de las secciones de Estrategias Globales y Economía Internacional, redactados originalmente en lengua castellana, pero solamente hemos podido incluir en este trabajo un número muy reducido, por razones obvias de espacio. En concreto, han sido dos artículos, muy extensos, de dos autores españoles, de reconocido prestigio en la escena internacional.

Procedemos, a continuación, a resaltar los aspectos explorados durante el análisis de los artículos, señalando las técnicas de traducción seguidas por los traductores.

Seguridad para la Europa post-Brexit http://prosyn.org/sHIXUales - 05/07/2016 Por Ana Palacio

Traductora: Maysa Kamel

MADRID - La nueva Estrategia Global de

Política Exterior y de Seguridad de la

Unión Europea, que se ha hecho esperar más de una década, ha visto por fin la luz y se erige en piedra de toque del proyecto europeo. La fecha de su anuncio inmediatamente después del voto del Reino

Unido a favor de salir de la UE-podría simbolizar su irrelevancia o, por el contrario, marcar el renacer del proyecto europeo. La estrategia, elaborada por la Alta Representante de la UE para Asuntos Exteriores y Política de Seguridad, Federica Mogherini, marca unas líneas directrices coherentes, está dotada de la

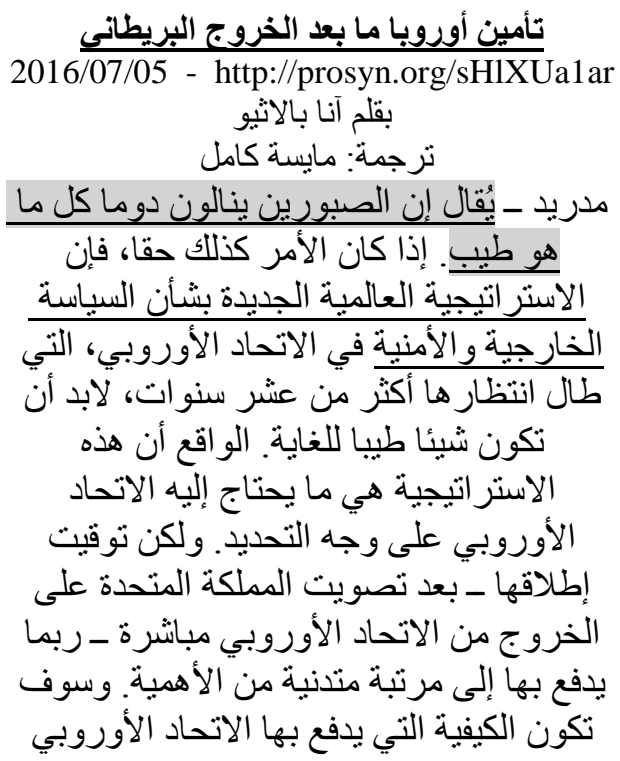


flexibilidad necesaria para la adopción de políticas concretas, y establece un equilibrio adecuado entre realismo y ambición, al reconocer las limitaciones de

la UE y poner de relieve las mejoras pendientes.

El planteamiento de la estrategia queda patente desde la primera frase:

"Necesitamos una Europa más fuerte". Supone un viraje con respecto a la filosofía de la estrategia anterior, publicada en 2003 y conocida por su muy criticada frase de apertura: "Europa no ha sido nunca tan próspera, tan segura ni tan libre".

Concretamente, la estrategia pone de manifiesto la importancia del inagotable soft power de la UE -sin rehuir posibles

futuras ampliaciones-, al tiempo que reconoce que el poder blando por sí solo no basta para garantizar la seguridad. Además, implícitamente establece la hoja de ruta acertada sobre el enfoque de la UE hacia el mundo. Formula una visión mucho más precisa para la resolución de los desafíos regionales que para los retos globales. El mensaje es cristalino: antes de desempeñar un papel de calado global, la UE debe aunar fuerzas y actuar unida hacia sus vecinos.

Se trata así de un marco intelectual ambicioso y realista, pero que carece de virtualidad propia. Para asegurar que la estrategia alcanza todo su potencial es preciso que los líderes europeos, en palabras de Mogherini, se "concierten". Y, por el momento, las señales no son halagüeñas.

"Brexit", que provoca turbulencias en los mercados globales y plantea serias dudas sobre el futuro de la Unión, ha eclipsado la presentación de la estrategia de seguridad, que apenas merece una mención en las conclusiones del Consejo Europeo del pasado 28 de junio. Es más, en lugar de inspirar la enérgica respuesta tan necesaria hoy entre los dirigentes de los 27 Estados Miembro (excluido el Reino Unido), el referéndum británico ha actuado de catalizador de intereses políticos

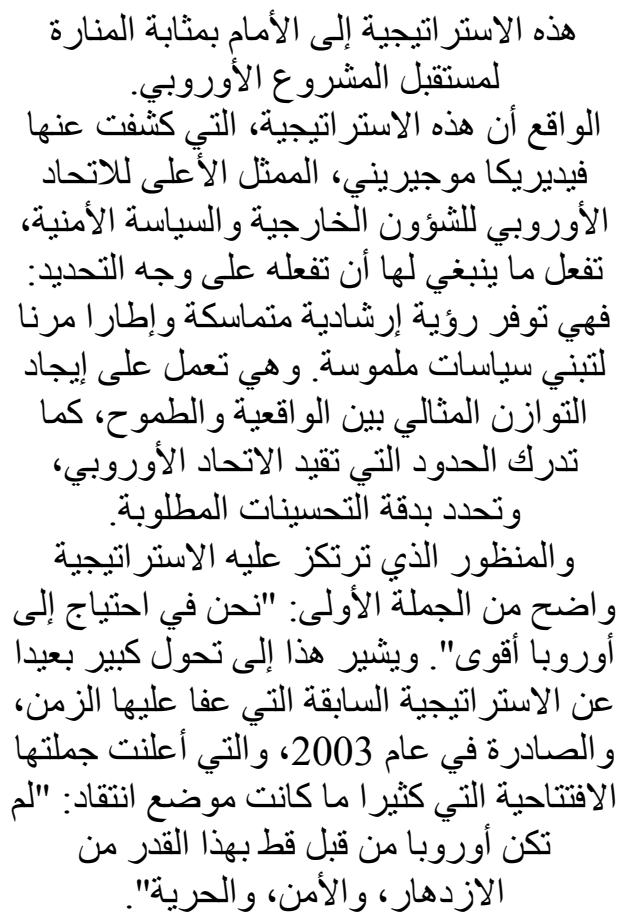


nacionales, cuando no de puras ambiciones personales.

Esta estrechez de miras, al acentuar la sensación de impotencia e ineptitud de la

UE, debilita su imagen en el mundo, e incluso ante los Estados miembro. Si no cambia esta percepción, Brexit podría suponer, como los pesimistas auguran, el declive definitivo de la UE. Si, por el contrario, los líderes de la UE se crecen ante el desafío que la salida del RU supone $\mathrm{y}$ unen fuerzas para aguantar el temporal y llevar a la práctica el plan esbozado en la Estrategia Global, la UE podría resurgir fortalecida de este episodio convulso.

En tiempos de incertidumbre, Europa debe decidir cómo enfrentarse a los retos existenciales que la asolan. Lo razonable pasa por apostar por las fortalezas colectivas y paliar las debilidades. Lo opuesto - la desbandada que los británicos podrían simbolizar- sería una temeridad. Pero el enfoque más peligroso -aquél que conllevaría un mayor grado de

conflictividad e inseguridad-consistiría en seguir fingiendo que existe una unión mientras cada cual va a lo suyo.

Los dirigentes de la UE han dejado escapar una oportunidad excepcional. Así, el último Consejo Europeo podría haber iniciado la reflexión necesaria sobre qué futuro queremos para la UE. Que la nueva estrategia de seguridad simbolice el comienzo de un nuevo capítulo para Europa o, por el contrario, el testamento de un proyecto en su lecho de muerte, dependerá de si los dirigentes europeos son capaces de superar su estrechez de miras y concertarse en el diseño de un futuro común. Las primeras reacciones no son prometedoras.

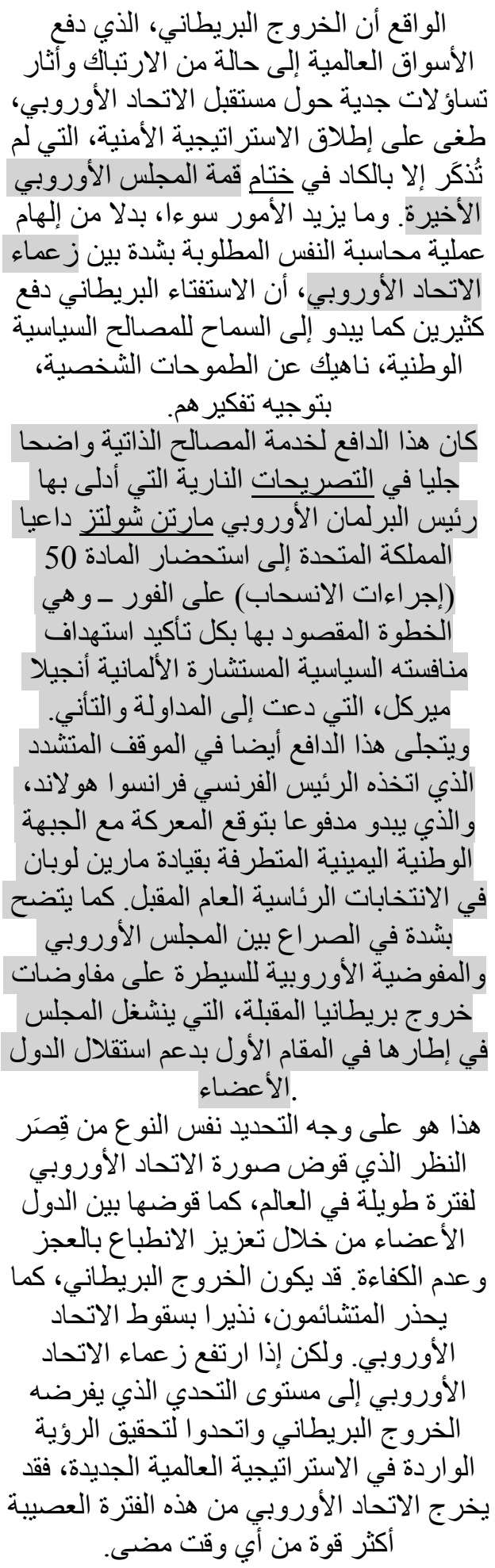




$$
\begin{aligned}
& \text { في الأوقات المضطربة، يتعين على أوروبا أن }
\end{aligned}
$$

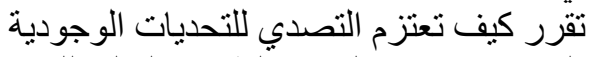

$$
\begin{aligned}
& \text { التي تو اجهها. ونتلخص الطريقة المتئلى للتقدم }
\end{aligned}
$$

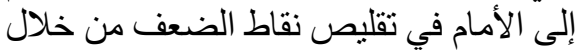

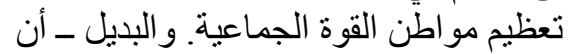

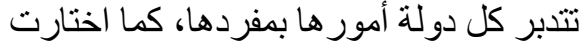

$$
\begin{aligned}
& \text { بريطانيا أن تفعل ـ هو التهور بعينه. أما النهج }
\end{aligned}
$$

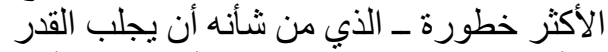

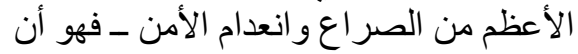

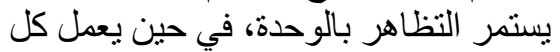

$$
\begin{aligned}
& \text { طرف بشكل مستقبل. }
\end{aligned}
$$

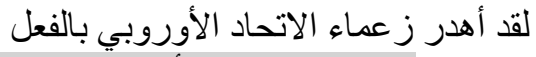

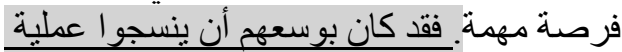

$$
\begin{aligned}
& \text { تحديد طموحات وتطلعات أوروبا ونيات وصياغة }
\end{aligned}
$$

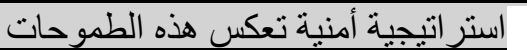

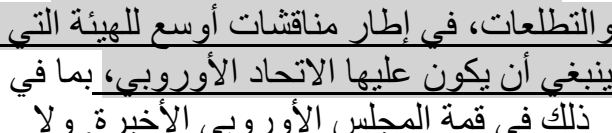

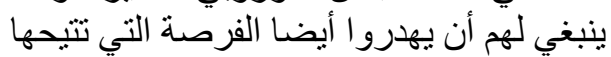

$$
\begin{aligned}
& \text { الاستر اتيجية الجديدة الآن. } \\
& \text { إن مثل هذه الفرص لا تسنح كل يوم. فقد تصبح الإنح الإنح }
\end{aligned}
$$

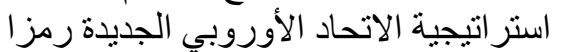

$$
\begin{aligned}
& \text { لبداية فصل جديد في المشروع الأوروبي، أو الأورئ }
\end{aligned}
$$

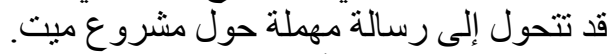

$$
\begin{aligned}
& \text { ويتوقف هذا المصير أو ذالك على قدرة زلئ عماء }
\end{aligned}
$$

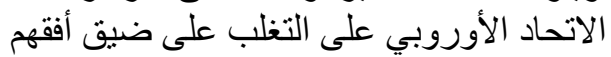

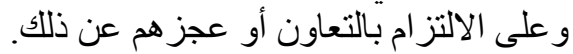

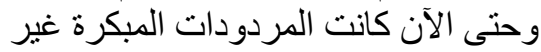

$$
\begin{aligned}
& \text { و اعدة. }
\end{aligned}
$$

\section{Análisis y comentario del artículo 1}

En el primer artículo, escrito por la diplomática española, Ana Palacio, exministra de Asuntos Exteriores de España, y con identificación del traductor -algo que no se ha cumplido siempre en la página web consultada, como veremos en el artículo 2- podemos decir que la traducción ha sido muy satisfactoria, en general, en lo que se refiere al contenido y a la adaptación al texto meta.

Las técnicas de traducción aplicadas, consciente o "inconscientemente", en este artículo han sido las tres expuestas más arriba, aunque en grado distinto. La amplificación se ha usado siguiendo las nuevas circunstancias de recepción del artículo traducido que, en este caso, coinciden, casi siempre, con las 
siguientes finalidades: actualización de la información, explicación de la información y contextualización de la información (Hernández, 2006: 132).

Con el fin de facilitar la visualización de las tres técnicas, si es el caso, aplicadas en un mismo artículo, hemos optado por resaltarlo de la siguiente manera: amplificación (subrayado y en color sombreado), compresión (sombreado) y elisión (subrayado). Esto se señalará, como es lógico, en el texto meta, pero, en el caso de la elisión, se hará sobre el texto origen, y en la compresión, en ambos textos, ya que no queda claramente reflejado en el texto traducido.

En este artículo, se puede observar claramente cómo se añaden en el texto meta dos párrafos y algunas frases, ausentes en el texto original, que hemos resaltado en su correspondiente lugar. En el primer caso, se trata de un amplio párrafo (más de 100 palabras), en el que el traductor intenta aportar más in formación y contextualiza el tema objeto de análisis en este artículo, agregando datos sobre la lucha interna y los intereses partidistas en Francia, Alemania e incluso en la propia Unión Europea, en relación con el "Brexit". En el segundo caso, aunque es menos extenso que el primero (30 palabras, aproximadamente), sí que añade información complementaria, pero en la misma línea de la argumentación esgrimida por la columnista, que invitaba a los líderes europeos a diseñar una estrategia de seguridad más amplia que refleje las aspiraciones y ambiciones del viejo continente.

Igualmente, se ha aplicado, aunque en menor medida y a penas de forma perceptible, la técnica de la compresión, ya que su uso no afecta de forma sustancial al conjunto del artículo, y porque se trata de una noticia de alcance internacional, donde es casi siempre necesario ampliar información, en vez de reducirla, como se verá en el artículo 2.

La compresión, por ejemplo, se da cuando hay que sintetizar elementos lingüísticos, debido a las nuevas necesidades del canal receptor y el nuevo formato que acoge el texto traducido (Hernández, 2006). En este primer artículo, esta situación se ha repetido, en más de una ocasión, pero sin llegar a repercutir en la comprensión y fluidez del texto meta. El autor ha recurrido a esta estrategia a causa de las necesidades y peculiaridades de la lengua árabe, ya que, en algunos casos, se podría percibir cierta carga informativa redundante en el texto original, y de ahí la necesidad acuciante de comprimir y adaptar dicho material en diferentes pasajes del artículo, con el fin de hacer que los detalles sean menos específicos, más breves y lo más concisos posible. A modo de ejemplo ilustrativo, hemos resaltado los fragmentos donde se ha dado esta circunstancia. En cuanto a la elisión, apenas hemos percibido su aplicación en este primer artículo, ya que el traductor ha sido totalmente fiel al contenido original del texto.

Cambio de escenario para Argelia

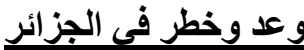


http://prosyn.org/vBtmTHHes $25 / 02 / 2016$

Por Javier Solana

MADRID - Los primeros meses de 2016 traen consigo el quinto aniversario de las Primaveras Árabes y, con él, los balances que, lamentablemente, son muy desalentadores. Durante todos estos años se ha seguido con detenimiento el transcurso de las revoluciones y, en muchos de los casos, su evolución en dramáticos conflictos que permanecen sin solución.

Sin embargo, hemos prestado menos atención a los países donde las revueltas se mitigaron cuando aún eran incipientes, como es el caso de Argelia. En los últimos días, su reforma constitucional y los efectos de la caída de los precios del petróleo han suscitado un mayor interés.

El 7 de febrero se aprobó una reforma constitucional que estaba prevista desde el año 2011. Entre otras modificaciones, incluye la limitación del mandato del presidente (el actual gobierna el país desde el año 1999) y el reconocimiento de algunas libertades fundamentales. Más allá de las críticas por ser insuficiente, esta reforma tiene lugar en un contexto delicado de incertidumbre política y económica, intensificadas por grandes desafíos externos.

El país se encuentra bloqueado políticamente por un supuesto consenso que paraliza la toma de decisiones. El presidente Abdelaziz Bouteflika se encuentra en un estado de salud delicado y sus apariciones públicas son muy escasas. Las próximas elecciones están previstas para el año 2019 y no está claro quién sucederá al hoy presidente que, ya en el 2014, no pudo desarrollar la campaña electoral debido a sus problemas de salud. Desde el año 2013, se han tomado medidas que restringen el gran poder que los servicios de seguridad e inteligencia militar ostentaban desde hace décadas. La destitución -el pasado mes de septiembredel que, durante 25 años, había sido jefe de los servicios de inteligencia, Mohammed
$2016 / 02 / 25$

http://prosyn.org/vBtmTHHar

$$
\begin{aligned}
& \text { بقلم خابيير سو لانا } \\
& \text { مدريد - بعد خمس سنو ات من بداية ما يسمى لإنائ }
\end{aligned}
$$

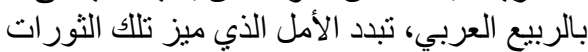

$$
\begin{aligned}
& \text { في البداية إلى حد كبير. في كثير من التئ الحالات، } \\
& \text { تطورت الثور ات إلى نز اعات داخلية وحشية }
\end{aligned}
$$

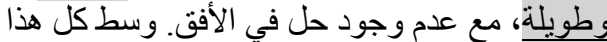

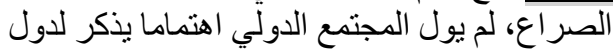

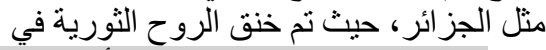

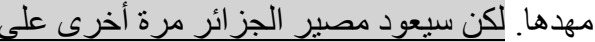

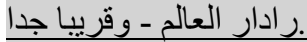

في يوم 7 فبر اير، و افق البرلمان الجزائري على الإدي

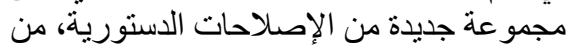

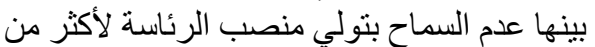

فترنين والاعتر اف ببعض الحضئ الحريات الأساسية.

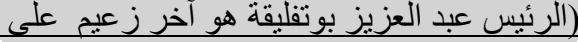

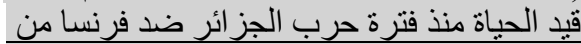

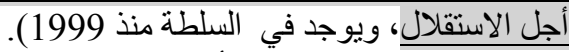

وتهدف هذه الخطو ات التئ وئي بدأت منذ عام 2011

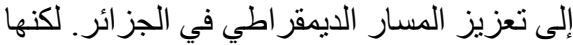

تعرضت لانتقادات على نطاق واسع بدعوى الجيز أنها غير كافية. - غافية

$$
\begin{aligned}
& \text { ومما لا شك فيه أن هذه الإصلاحات تأتي في وقت }
\end{aligned}
$$

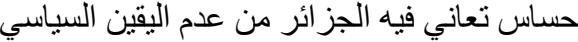

$$
\begin{aligned}
& \text { و الاقتصادي. وقد أحدث "الإجماع" الذي الذي كان من النين }
\end{aligned}
$$

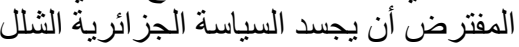

$$
\begin{aligned}
& \text { لسنو ات عديدة على مستوى صنع القرار. }
\end{aligned}
$$

$$
\begin{aligned}
& \text { ولم يظهر بوتفليقة المريض علنا منذ أكثر من سنة، }
\end{aligned}
$$

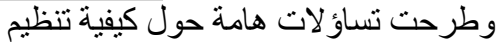

$$
\begin{aligned}
& \text { الانتخابات الرئاسية سنة الات هاتة 2019. إن الجهود }
\end{aligned}
$$

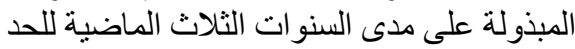

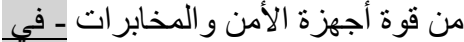

$$
\begin{aligned}
& \text { سبتمبر، دفعت بمحمد مدين، الذي كان رئيس جهاز }
\end{aligned}
$$

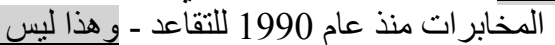

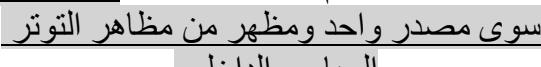

$$
\begin{aligned}
& \text { السياسي الداخلي. }
\end{aligned}
$$

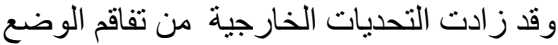

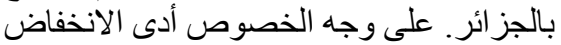

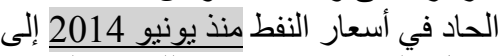

$$
\begin{aligned}
& \text { استفحال ألنموذج الاقتصادي للبلاد، بالنظر إلى بلى }
\end{aligned}
$$


Mediene, ha sido el movimiento más sonado de esta transformación.

La caída de los precios del petróleo puede ser un elemento aún más desestabilizador.

Este fenómeno pone en evidencia la

enorme dependencia del sector de

hidrocarburos -que proporcionan al país el 97\% de sus ingresos por exportaciones- $y$

la insostenibilidad de su modelo

productivo. Asimismo, hace imposible el mantenimiento de la amplia variedad de subsidios a la población, que

tradicionalmente han servido de bálsamo para evitar protestas sociales. A día de hoy

el gobierno ya ha tenido que aumentar

algunos impuestos y los precios de los combustibles, la electricidad, el gas y otros.

Si se mantienen los bajos precios del petróleo, el gobierno podría verse obligado a implementar medidas más drásticas $\mathrm{y}$,

finalmente, alterar la balanza de la estabilidad social.

Otro elemento que, durante estos años, ha evitado el aumento de protestas ha sido el temeroso recuerdo de la guerra civil de los 90, donde los enfrentamientos acabaron con la vida de más de 150.000 personas. Sin embargo, con el paso del tiempo hay cada vez más jóvenes que la recuerdan con menor intensidad. Si disminuyen los desincentivos a las protestas y continúa la difícil coyuntura económica, la situación puede desembocar en tensiones y revueltas. La diversificación de la economía argelina es vital en este sentido.

Por otro lado, Argel cuenta con un panorama exterior complicado. Tras las revueltas de Túnez, la guerra en Libia, la rebelión de los tuareg en Malí y, especialmente, el atentado en la planta de gas argelina de In Amenas, en los últimos años ha reconsiderado su política exterior. Pese a que en la constitución argelina se

prohíba explícitamente cualquier intervención militar en los asuntos internos de otros países, la gran preocupación por la seguridad doméstica ha aumentado su interés por contar con estructuras estatales fuertes a su alrededor, que disuadan a los grupos extremistas. Un ejemplo es su

$$
\text { صناعة النفط و الغاز التي تمثل تماما 97٪ من دخل }
$$

ويوحي تر اجع عائدات النفط أن الحكومة الجز ائرية

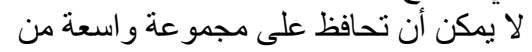

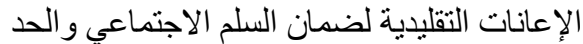

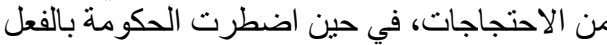

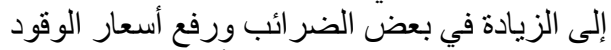

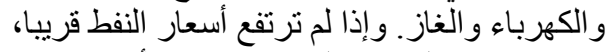

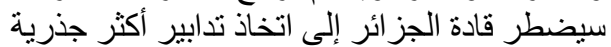
قد تعرض الاستقرار الاجتماعي للخطر الخراير.

ومن المؤكد أن بعض العو امل قد تساعد على درء

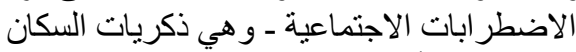

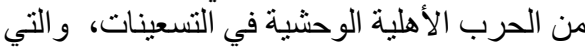

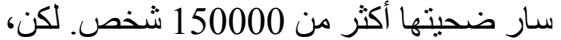

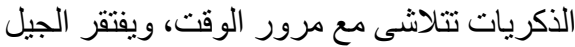

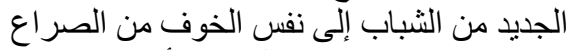

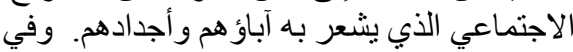

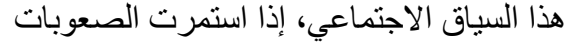
الاقتصادية و الاحتجاجات فإن الثورة الثرة قد لا تكون

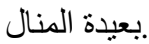

$$
\text { لتجنب مثل هذه النتيجة، ينبغي على الحكومة }
$$
الجز ائرية العمل بسر عة لتنويع الآتصـاد. ولكن مثل لئل

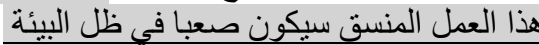

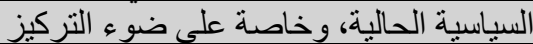
الحكومي على التحديات الأمنية في جوارية ضيو الجزئرئ.

ونظر اللثورة في تونس، و الحرب في ليبيا، وتمرد

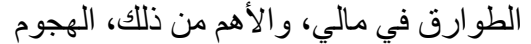

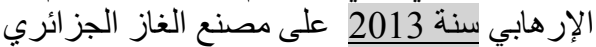

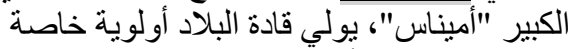

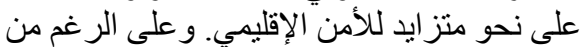

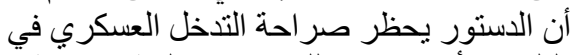

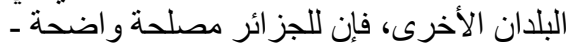

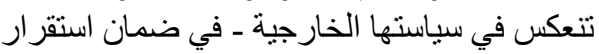

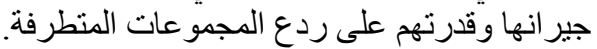

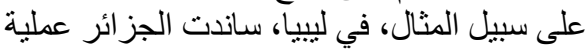

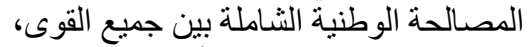

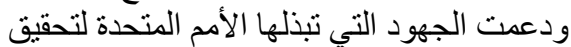
الاستقز ار في البلاد.

وقد اعترفت الو لايات المتحدة وأوروبا بجهود قيادة

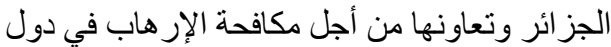
الجوار . وبالنسبة للاتحاد الأوروبي، يكتسي الأري 
actuación en Libia, donde ha abogado por un proceso de reconciliación nacional inclusivo de todas las fuerzas, apoyando los esfuerzos de Naciones Unidas.

La colaboración de Argel y su liderazgo en los esfuerzos antiterroristas en la región han sido especialmente reconocidos por Estados Unidos y Europa. Para la Unión Europea Argelia es un país de gran importancia. Su cercanía y los intereses comunes en la estabilidad del Norte de África y el Sahel, así como las cuestiones de seguridad energética, hacen de Argelia un aliado clave, con quien la Unión

Europea quiere avanzar en sus relaciones. Sin embargo, la cooperación regional podría ser mucho más intensa si Argelia y Marruecos mantuvieran relaciones diplomáticas. Lograr una integración regional estable en el Magreb sería enormemente beneficioso para todos, en términos comerciales, económicos y de seguridad. El restablecimiento de las relaciones con Marruecos, rotas desde hace cuarenta años, desbloquearía las relaciones entre los países del Magreb, paralizadas por estas dos grandes potencias del norte de África.

En las instituciones de integración continentales, Argel puede posicionarse como un actor de peso. El próximo mes de julio expira el mandato de la actual Presidenta de la Comisión de la Unión Africana y, en las últimas semanas, se han escuchado voces que proponen un candidato argelino para sucederla. Argelia sería, en ese caso, el primer país del norte en presidir la Comisión de la Unión

Africana y tiene a su favor el apoyo constante que ha prestado a la institución. Todos los comisarios de Seguridad y Paz de la Unión Africana han sido argelinos y el país se ha comprometido especialmente con la seguridad regional, promoviendo el acuerdo de paz en Malí y albergando las conversaciones sobre la situación en Libia.

Argelia se encuentra ante un escenario nuevo. Los enormes desafíos que le presentan los precios del petróleo y la evolución de sus vecinos evidencian la

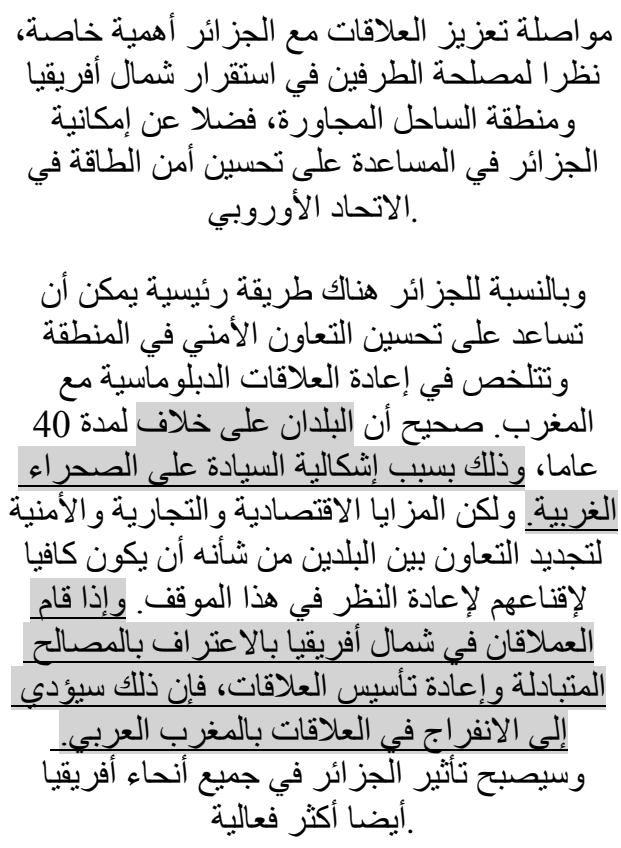


necesidad imperiosa de cambio. De su habilidad para diversificar la economía y desbloquear el sistema político, así como de sus esfuerzos diplomáticos, depende que, en unos años, sea un país estable que ocupe un lugar de primer orden en su región y en el continente.

\section{Análisis y comentario del artículo 2}

En el segundo artículo, cuyo autor es el diplomático español, y antiguo Alto Representante de la Política Exterior y de Seguridad de la UE y Secretario General de la OTAN, Javier Solana, podemos adelantar que la traducción difiere, en líneas generales, de la que hemos podido analizar en el primer artículo. El texto, a diferencia del anterior, no va acompañado del nombre del traductor y son claramente perceptibles algunos errores menores de índole gramatical y/o de fidelidad manifiesta al texto origen. A pesar de la ausencia de omisiones en el texto meta, sí se puede observar que el traductor ha manejado, con bastante habilidad, la compresión y reproducción de la misma información en pasajes distintos pero afines de contenido, sin llegar por ello a constituir una elisión o compresión total, salvo en los casos señalados. Este recurso utilizado por el traductor, a lo largo de su labor traslativa, le ha llevado, en muchos casos, a evadirse de la "literalidad y fidelidad textual" -muy deseada en la traducción de este género- y refugiarse más en la traducción libre y en la adaptación terminológico-semántica. Digo deseada siempre y cuando la estructura final no adopta significados desconocidos o indescifrables para el lector meta.

La amplificación ha sido la técnica a la que más ha recurrido el traductor en este artículo, con el fin de hacer más asequible al lector árabe la compresión del texto origen. En todos los casos en los que hemos resaltado la ampliación de la información en el texto meta, viene justificada por las tres finalidades expuestas al principio del comentario al artículo 1 (actualización, explicación y contextualización de la información).

En cuanto a la compresión, se perciben varias formas: cuando se intenta resumir un pasaje del texto original, añadir o resaltar detalles más específicos dentro de este o cuando se recurre a la brevedad o concisión de la misma idea esgrimida. En estos ejemplos, podemos reflejar estos aspectos: “... el restablecimiento de las relaciones con Marruecos, rotas desde hace

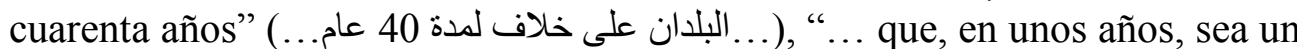
país estable que ocupe un lugar de primer orden en su región y en el

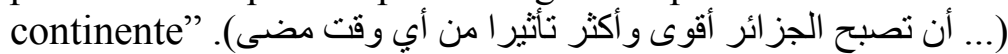

En lo que respecta al uso de la técnica de elisión, que se practica con mucha frecuencia en los textos de carácter informativo o interpretativo, en los que se podrían "imputar" desde párrafos completos hasta frases o elementos 
léxicos, en esta variedad textual su aplicación, por contrario, es más bien escasa, por no decir nula. Esto se debe, sobre todo, al formato electrónico utilizado en esta web, y en otras aún más, donde la cuestión de espacio, antaño primordial, deja de cobrar vigencia.

En este caso, hemos señalado dos ejemplos que, aunque no afecten a la compresión del conjunto del artículo, sí han sido eliminados, sin razón aparente, por el traductor en la versión traducida: "En los últimos días, su reforma constitucional y los efectos de la caída de los precios del petróleo han suscitado un mayor interés” y “...quién sucederá al hoy presidente que, ya en el 2014, no pudo desarrollar la campaña electoral debido a sus problemas de salud".

\section{Conclusión}

En este trabajo, que ha abordado aspectos relevantes de la traducción de la argumentación en la combinación español/árabe/español y la aplicación de las técnicas específicas de la traducción periodística a este género textual, se han podido cumplir, a nuestro juicio, los objetivos esbozados al principio de este artículo.

En la parte teórica, se ha revisado la bibliografía específica relacionada con la argumentación y su traducción, y se han resaltado las peculiaridades de la combinación español-árabe, señalando que los escritores árabes han tenido históricamente la opción de desarrollar la estrategia de la contraargumentación, aunque prefieren desarrollar la argumentación a fondo (Sa'adeddin, 1987).

En la parte práctica, dedicada al análisis y aplicación de las técnicas específicas de traducción a dos artículos de opinión, se ha podido comprobar el grado de uso de las tres técnicas (amplificación, compresión y elisión) en cada caso. Además, se ha podido constatar que la amplificación es la estrategia de traducción predominante, en esta variedad textual, en la traslación de un texto redactado originalmente en español al árabe.

\section{References:}

Baba, Ch. (2011). "La traducción de los elementos culturales en el texto periodístico español. Estudio y análisis de términos de la Revuelta Árabe". Trabajo Fin de Máster (inédito). Universidad de Granada.

Baya, M.L. (2015). "El error gramatical en la traducción de prensa al árabe. Estudio y análisis". Revista Opción, Año 31, Núm. Especial 2, pp. 102-121. Baya, M.L. (2007). "Traducción y medios de comunicación. Notas acerca de los errores gramaticales más comunes en la prensa árabe". Revista Puentes, Vol. 1, núm. 8, pp.: 41-52. Baya, M.L (2005). "Traducción de textos periodísticos: español-árabe. Diez años de experiencia en una agencia internacional de noticias". En PLAZA, N. et al. (coords.). El español, lengua 
de cultura, lengua de traducción. Pp. 405-414. Cuenca: Ediciones de la Universidad de Castilla - La Mancha \& Editorial Atrio.

Beaugrande, R. y Dressler, W. (1981). Introduction to Text linguistics. London: Longman.

Biber, D. (1988). Variation across Speech and Writing. Cambridge: Cambridge University Press.

Casaús, J.M. y Núñez, L. (1991). Estilo y géneros periodísticos. Barcelona: Editorial Ariel.

Darwish, A. (2005). "Modern Arabic in the Media between Sustainability and Crystal Gazing: Haphazard Translation and Transfer of Knowledge and Idiom". At-Turjuman Online. Vol. 2, Issue 03. http://www.translocutions.com/translation/index.html. Consultado el $21 / 06 / 2016$

Darwish, A. (2004). "Al-tarŷama fil i'lām al-'arabī wa al-mas'ala azzanburiya" (La traducción en los medios de comunicación árabe y la cuestión zanburi). At-Turjuman Online. Vol. 1, Issue 14. http://www.translocutions.com/translation/index.html. Consultado el 20/06/2016.

El Khaoua, S. y Lahmidi, A. (2014). "El proceso de producción y traducción de la información en la Agencia Marroquí de Noticias (MAP)". Trabajo Fin de Grado (inédito). Universidad de Granada.

Ghignoli, A. y Montabes, A. (2014). "La traducción y los géneros periodísticos". Revista Mutatis Mutandis, Vol. 7, Núm. 2, pp.: 386-400.

Hatim, B. (1989). "La contraargumentación y la dinámica del texto: una aproximación sobre el proceso de traducción del árabe y viceversa" (al-ŷadal al-mu'ārị̣ wa dināmiat al-naṣ: 'aḍ̂à' 'ala 'amaliyat aṭ-tarŷama min al'arabiya wa' ilay-ha), Turjuman, 1 (1), pp.37-47.

Hatim, B. (1997). English-Arabic/Arabic-English translation: a practical guide. London: Saqi books

Hatim, B y Mason, I. (1995). Teoría de la traducción: Una aproximación al discurso. Barcelona: Ariel. (Versión original: Discourse and the translator. London: Longman, 1990).

Hernández, M J J. (2008). "La traducción periodística en los diarios españoles de información general". En PEGENAUTE, L. et al. (eds.). Actas del III Congreso Internacional de la Asociación Ibérica de Estudios de Traducción e Interpretación. La traducción del futuro: mediación lingüistca y cultural en el siglo XXI. Vol. 2, pp. 359-368. Versión electrónica disponible en la web de la AIETI: <http://www.aiet.

Hernández, M M. (2006). "Técnicas específicas de la traducción periodística". Quaderns. Revista de Traducció. Vol. 13, pp.: 125-139. 
Hernández, Maj. (2005). "Prensa y traducción", en CORTÉS, C. y HERNANDEZ Ma J. (Coords.). La traducción periodística. Pp. 166-171. Cuenca: Ediciones de la Universidad de Castilla - La Mancha.

Hurtado Albir, A. (2004). Traducción y Traductología. Introducción a la Traductología. Madrid: Editorial Cátedra.

Leñero, V. y Marín, C. (1986). Manual de periodismo. México: Grijalbo.

Mezel, M. (2012). La traducción de la exposición y la argumentación en la prensa árabe. Una aproximación al análisis del discurso. Tesis Doctoral inédita. Universidad de Granada.

Müller, J. (1990). La noticia interpretada. Santiago de Chile: Atena.

Peñaranda, R. (2012). “Géneros periodísticos: ¿Qué son y para qué sirven?”. Redacción Periodística UNDAV. http://redaccionperiodisticaundav.blogspot.com.es/2012/08/que-son-losgeneros-periodisticos.html. Consultado el 18/06/2016.

Sa'deddin, M. A. (1987). "Target-World Experiential Matching: The Case of Arabic/English Translation". Quinquereme-New Studies in Modern Languages 10 (2), pp.137- 164.

Torrico, E. (1989). Periodismo, apuntes teórico-técnicos. La Paz: Andina.

Toulmin, S. (1958). The uses of Argument. Londres: Cambridge University Press.

Trotter, W. (2000). Translation Salience: A Model of Equivalence in Translation (Arabic/English). Tesis Doctoral. Department of Semitic Studies, University of Sydney <http://ses.library.usyd.edu.au/bitstream/2123/497/2/adtnu20031205.094659 03part2.pdf > (Consultado el 15 de junio de 2016). 